\title{
Efeitos de uma cultura performática: um diálogo com estudantes da pós-graduação em educação no Brasil
}

Efectos de una cultura performativa:

Un diálogo con estudiantes de postgrado en educación en Brasil

Effects of a performational culture:

A dialogue with postgraduate students in education in Brazil

\section{Volumen 21, Número 2 \\ Mayo - Agosto \\ pp. 1-27}

\author{
Ana Paula Antonello \\ Luci dos Santos Bernardi
}

\section{Citar este documento según modelo APA}

Antonello, Ana Paula., y Bernardi, Luci dos Santos. (2021). Efeitos de uma cultura performática: um diálogo com estudantes da pós-graduação em educação no Brasil. Revista Actualidades Investigativas en Educación, 21(2), 1-27. Doi. 10.15517/aie.v21i2.46821 


\title{
Efeitos de uma cultura performática: um diálogo com estudantes da pós-graduação em educação no Brasil
}

\author{
Efectos de una cultura performativa: \\ Un diálogo con estudiantes de postgrado en educación en Brasil \\ Effects of a performational culture: \\ A dialogue with postgraduate students in education in Brazil
}

\section{Ana Paula Antonello ${ }^{1}$ Luci dos Santos Bernardi2}

\begin{abstract}
Resumo: No atual cenário da Pós-graduação stricto sensu no Brasil, a relação entre os níveis macro de definição das suas políticas e o nível micro de sua aplicação local caracteriza um cenário que exige do discente produção e desempenho, uma cultura da performatividade, ancorada em resultados que impõem metas de produção intelectual a partir de critérios de avaliação. Tal cenário instigou o desenvolvimento da pesquisa que teve por objetivo identificar como se configura a cultura da performatividade discente nos programas de Pós-graduação em Educação da região oeste de Santa Catarina-Brasil, cujos resultados apresentamos no presente artigo. A pesquisa se caracteriza como de cunho qualitativo quanto à abordagem do problema e exploratória quanto ao escopo. A coleta e análise da materialidade empírica ocorreu no decorrer de 2018. O corpus de dados constituiu-se por documentos normativos, fichas de avaliação da Coordenação de Aperfeiçoamento de Pessoal de Nível Superior (Capes) e entrevistas com estudantes. A investigação está organizada à luz da Análise Textual Discursiva, com aporte teórico em Stephen Ball e Pierre Bourdieu. A partir do estudo realizado, podemos inferir que a cultura da performatividade discente é regulada pelo sistema no qual esses sujeitos estão inseridos, que exerce influência sobre o modo como se dá o desenvolvimento do cenário formativo. Os estudantes sentem-se pressionados e elencam o tempo como fator dificultador na produção e no desenvolvimento epistemológico.
\end{abstract}

Palavras-chave: produtividade, estudantes, pós-graduação, avaliação.

Resumen: En el actual escenario del Postgrado stricto sensu en Brasil, la relación entre los niveles macro de definición de sus políticas y el nivel micro de su aplicación local caracteriza un escenario que exige de la persona discente producción y desempeño, una cultura de la performatividad, anclada en resultados que imponen metas de producción intelectual a partir de criterios de evaluación. Este escenario propició el desarrollo de la investigación que tuvo como objetivo identificar cómo se configura la cultura del desempeño estudiantil en los Programas de Posgrado en Educación de la región occidental de Santa Catarina-Brasil, cuyos resultados se presentan en este artículo. La investigación es cualitativa en cuanto al abordaje del problema, y de alcance exploratorio. El trabajo de recolección y análisis de material empírico se llevó a cabo durante el año 2018. El corpus de datos se constituyó por documentos normativos, fichas de evaluación de la Coordinación para la Perfeccionamiento del Personal de Educación Superior (Capes) y entrevistas con estudiantes. La investigación está organizada a la luz del Análisis Textual Discursivo y con suporte teórico en Stephen Ball y Pierre Bourdieu. A partir del estudio realizado, podemos inferir que la cultura de la performatividad discente se regula por el sistema en el cual esos sujetos están insertados, que ejerce influencia sobre el modo en que se da el desarrollo del escenario formativo. El estudiantado se siente presionado y cataloga el tiempo como factor de dificultad en la producción y en el desarrollo epistemológico.

Palabras clave: productividad, estudiantes, posgrado, evaluación.

\footnotetext{
1 Universidade Comunitária da Região de Chapecó, Santa Catarina, Brasil. Dirección electrónica: anpaulaantonello@unochapeco.edu.br ORCID: https://orcid.org/0000-0001-8058-9473

2 Universidade Regional Integrada do Alto Uruguai e das Missões, Río Grande del Sur, Brasil. Dirección Electrónica: lucisantosbernardi@gmail.com ORCID: http://orcid.org/0000-0001-6744-9142
}

Artículo recibido: 18 de noviembre, 2020

Enviado a corrección: 26 de febrero, 2021

Aprobado: 29 de abril, 2021 


\begin{abstract}
In the current scenario of stricto sensu Post-graduation in Brazil, the relationship between the macro levels of definition of their policies and the micro level of their local, application characterizes a scenario that requires the student to produce and perform, a culture of performativity, anchored in results that impose intellectual production goals based on evaluation criteria. This scenario prompted the development of research that aimed to identify how the culture of student performance is configured in the Graduate Programs in Education in the western region of Santa Catarina-Brazil, whose results are presented in this article. The research is qualitative in terms of approaching the problem and exploratory in scope, and the work with the collection and analysis of empirical materiality took place during 2018. The data corpus consisted of normative documents Coordination for the Improvement of Higher Education Personnel (Capes) evaluation sheets and interviews with students. The investigation is organized in the light of Discursive Textual Analysis and with theoretical contribution in Stephen Ball and Pierre Bourdieu. From the study, we can infer that the culture of student performativity is regulated by the system in which these subjects are inserted, which influences how the development of the training scenario takes place. Students feel pressured and time stamped as a factor hindering production and epistemological development.
\end{abstract}

Keywords: productivity, students, postgraduate, evaluation.

\title{
1. Introdução
}

O presente trabalho apresenta parte dos resultados de uma pesquisa ${ }^{3}$ que visou identificar como se configura a cultura de performatividade discente no âmbito da Pósgraduação stricto sensu brasileira, tendo como foco de análise os programas de Pósgraduação em Educação da região Oeste de Santa Catarina e como base os conceitos de campo e habitus de Pierre Bourdieu. É um estudo que corrobora para as tensões existentes no campo acadêmico em relação à avaliação da Coordenação de Aperfeiçoamento de Pessoal de Nível Superior (Capes) e aos parâmetros de produtividade macroestruturais que condicionam formas de atuar no espaço da Pós-graduação stricto sensu no país.

O processo formativo dos estudantes de Pós-graduação perpassa as paredes de uma sala de aula, exige esforços individuais e coletivos que só eles próprios conseguem narrar. Durante esse percurso, experienciam diferentes situações, adaptando-se ao contexto espaço/temporal no qual estão inseridos, ao sistema avaliativo e às demais condições que são impostas pelos programas de Pós-graduação (PPG). É preciso inserir no cotidiano a frequência nas disciplinas, a participação e a organização de eventos, o tempo de estudo e o empenho para dissertar. Todas essas demandas implicam algo chamado performance, e o desempenho no curso é medido pelo desenvolvimento dessas diferentes atividades. Visibilidade e performatividade tornam-se elementos essenciais para o crescimento e 0 sucesso acadêmico. Eles definem o status atual dos estudantes e professores de cada programa. Mas como se dá esse processo? Em que consiste a performance?

\footnotetext{
${ }^{3}$ Dissertação intitulada "A cultura da performatividade discente no contexto da pós-graduação em educação na região Oeste catarinense" (Antonello, 2018).
} 
Embora sendo uma discussão recente, já possui uma trajetória significativa, sobretudo nos países anglo-saxões, revela Pereira (2013), que tem estudado o tema desde a década de 1980. As obras escritas nos mostram os caminhos até se chegar a uma definição de performance. Artigos escritos por Bianchetti e Machado (2009), Bianchetti e Valle (2014), Ball (2004; 2005; 2010), Trein e Rodrigues (2011) e outros abordam com veemência a visão geral de produção intelectual como algo mercadológico que vem perpassando as questões de solidariedade e até mesmo vem descentralizando os sujeitos, produzindo um deslocamento das sociedades para algo controlador.

Compreender a cultura da performatividade discente no contexto da Pós-graduação stricto sensu em Educação é o que mobiliza o presente trabalho. O termo "performatividade" é pouco conhecido no campo educacional. Porém, em contraponto, cada vez mais colocamse em evidência as consequências que esse modo de regulação imprime na Pós-graduação e seus desdobramentos, com trabalhos voltados, prioritariamente, para o professor pesquisador. Tal foco nos colocou não uma lacuna, mas uma interrogação e uma potencialidade de pesquisa ao olhar para o estudante.

O trabalho apresentado voltou-se a duas instituições: a Universidade Comunitária da Região de Chapecó (Unochapecó) e a Universidade Federal da Fronteira Sul (UFFS), ambas localizadas no município de Chapecó, no oeste de Santa Catarina, Brasil. Dos programas de pós-graduação ofertados por elas, foram selecionados aqueles que ofertam cursos stricto sensu em Educação e, também como delimitação, foram escolhidas as turmas de ingressantes 2016/2. Chegou-se, com esses critérios, a um universo de 37 alunos, sendo que 12 aceitaram participar da pesquisa e dão voz a este trabalho. Quatro deles são da UFFS e oito da Unochapecó. Na seção de metologia, são descritos os demais procedimentos metodológicos adotados. Na sequência, apresentamos os referenciais teóricos do trabalho.

\section{Referentes teóricos}

\subsection{Performatividade e pós-graduação: o contexto e o aporte teórico}

Como pesquisadores, encontramo-nos atrelados a parâmetros de produtividade macroestruturais que condicionam formas de atuar no espaço da Pós-graduação stricto sensu. A relação entre os níveis macro de definição das políticas para a área da Pós-graduação no Brasil e o nível micro de seu desenvolvimento local configurou um cenário que exige produção acadêmica, desempenho/performance, uma cultura de performatividade ancorada em resultados que impõem metas de produção intelectual a partir de critérios de avaliação de 
desempenho. Nessa sessão, compartilhamos o aporte teórico e as reflexões que nos permitiram compor o contexto acerca da Performatividade e da Pós-graduação.

\subsection{Um Diálogo com Stephen Ball e Pierre Bourdieu: aproximando-se do campo}

Os sujeitos que pertencem à área da educação, de uma maneira ou de outra, acabam performando, ou seja, atuando, desenvolvendo este ou aquele papel no contexto educacional. Talvez a expressão em si não seja comum, o que nos instiga a uma investigação de seu significado. Como abordamos os termos "Cultura" e "Performatividade", vamos definir cada um, visando reduzir a fragilidade dos conceitos, relacionando-os para compreender a essência do que buscamos.

$\mathrm{Na}$ atualidade, o termo "cultura" passou a ser utilizado na sua forma plural, "culturas", pois vivemos um cenário de grande heterogeneidade/pluralidade. Pensamos culturas como categoria teórica a ser estudada em um determinado tempo e espaço. Cultura é produção humana, incluindo desde objetos até as ideias, além de toda a vivência cotidiana. Incluímos aqui a da performatividade.

A palavra performance vem do verbo inglês to perform, significando realizar, completar, executar ou efetivar. Performance, então, remete a desempenho, ou seja, “...capacidade de uma conduta em um determinado domínio (...)" (Dolz e Edmée, 2004, p. 10).

O termo desempenho/performance tornou-se objeto de um debate científico a partir de Noam Chomsky4, que começou a utilizá-lo de modo sistêmico no campo da linguística gerativa. Vale notar a contribuição de Santos (2004, p. 152), que define a performatividade como sendo “(...) uma tecnologia, uma cultura e um modo de regulação que emprega julgamentos, comparações e termina se revelando como meio de controle, de desgaste e de mudança (...)".

Stephen J. Ball a define como:

(...) um sistema que implica julgamento, comparação e exposição, tomados respectivamente como formas de controle, de atrito e de mudança. Performances de sujeitos individuais ou organizações servem como medidas de produtividade ou resultados, como formas de apresentação da qualidade ou momentos de promoção ou inspeção. Elas significam, encapsulando ou representando um valor, a qualidade ou a valia de um indivíduo ou de uma organização dentro de um campo de julgamento. (2010, p. 38)

\footnotetext{
4 Noam Chomsky nasceu na Filadélfia, em 1928. Além de ser um conceituado linguista, é considerado um dos mais importantes pensadores da atualidade e um importante crítico de esquerda.
} 
Ball (2004) destaca que a performance se dá por via da produção. Essa, como ele aponta, está sendo constantemente avaliada. Constitui-se, assim, um mecanismo de controle, "um meio de regulação", uma "corrida" espaço/temporal para desenvolvimento/produção intelectual. Sob esse ponto de vista, a performance do pesquisador se dá dentro de um campo e a atuação dos pesquisadores caracteriza o sentido do campo científico, elemento que garante o seu movimento e produção/acumulação do capital científico. Essa medida de regulação visa a busca pela excelência, na qual pesquisadores (docentes e discentes) são constantemente cobrados. Precisam produzir, mostrar resultados, elevar o nível de produção, publicar em veículos qualificados, atendendo aos princípios avaliativos existentes. Desse modo, a performance aparece como algo voltado à produção, derivado de objetivos e metas estabelecidas não só pelas instituições/programas de Pós-graduação, mas também pela Capes, que visam assegurar a qualidade dos Cursos de Mestrado e Doutorado no Brasil.

Para compreensão do movimento dentro da Pós-graduação, ancoramo-nos também em Bourdieu, utilizando os conceitos de campo, habitus e capital científico, pois são fundamentais na análise e compreensão da cultura da performatividade discente. A priori, a produção de Bourdieu explica que construir um objeto científico é, antes de qualquer coisa, romper com o senso comum, ir além do pré-construído, já que este está por toda parte.

O campo de pesquisa é formado por uma estrutura, possui uma base de sustentação, um centro, e se desdobra a partir de instituições/programas de Pós-graduação/grupos de pesquisa, pesquisadores etc. Nesse espaço estruturado ocorrem disputas pela produção intelectual:

O campo científico, enquanto sistema de relações objetivas entre posições adquiridas (em lutas anteriores) é o lugar, o espaço de jogo de uma luta concorrencial. O que está em jogo especificamente nessa luta é o monopólio da autoridade científica definida, de maneira inseparável, como capacidade técnica e poder social; ou, se quisermos, o monopólio da competência científica, compreendida enquanto capacidade de falar e de agir legitimamente (isto é, de maneira autorizada e com autoridade), que é socialmente outorgada a um agente determinado. (Bourdieu, 1983, p. 122)

Sobre habitus, conforme Setton (2002, p. 61), “(...) a palavra latina (habitus)-utilizada pela tradição escolástica, traduz a noção grega hexis utilizada por Aristóteles para designar então características do corpo e da alma adquiridas em um processo de aprendizagem". O conceito de habitus é, ao mesmo tempo, uma maneira de pensar e de agir apreendida ao longo 
de certa trajetória social e é determinante mesmo sem a consciência de sua existência. É um sistema aberto que engloba o que o agente incorpora durante sua vivência em um determinado meio social. Representa a correspondência entre as práticas individuais e as condições sociais. O habitus mostra, portanto, um estilo de vida em que o agente consegue desenvolver e apresentar julgamento nas mais diversas áreas.

Agregamos aos conceitos de campo e habitus o de capital científico, “(...) uma espécie particular do capital simbólico que consiste no reconhecimento atribuído pelo conjunto de pares-concorrentes no interior do campo científico." (Bourdieu, 2004, p. 26). A aquisição do capital científico exige tempo, já que a agregação do capital se dá via participação em bancas (de teses, concursos...), eventos, cerimônias, reuniões, publicações, entre outros. O capital é, então, o título compensatório recebido como produto de tais participações.

Dentro desse campo, desenvolvem-se ações a partir do habitus em busca de um prestígio acadêmico. Busca-se, com essas atividades, acumular capital científico, ampliando as possibilidades de alcançar alguns prestígios e poderes inerentes ao campo. $\mathrm{O}$ agente pesquisador ou sujeito performativo, como empregado aqui, está dentro de um sistema macroestrutural (Pós-graduação), envolvido por microrrelações (com os demais sujeitos) que estão na busca do capital científico, a fim de chegar ao topo das relações existentes dentro do campo.

A partir dessa compreensão, a investigação estabelecida levou-nos a observar que as condições às quais os pesquisadores se submetem em busca de um status e de capital científico acabam se tornando algo desgastante, pois, para a manutenção dos sujeitos dentro do campo, deve-se seguir regras rígidas. Dessa forma, os agentes, muitas vezes, doam-se ao máximo e submetem-se a condições mecânicas de produção intelectual que acabam por esgotar até mesmo suas capacidades físicas e emocionais.

\subsection{O Campo Capes: atuação, produção e performance}

Na verdade, você me faz essa pergunta e eu me sinto pequena porque eu nem sei tudo o que a Capes pode avaliar da gente, do programa, o que precisa. (D0655).

\footnotetext{
${ }^{5} \mathrm{~A}$ fim de preservar a identidade dos sujeitos ouvidos ao longo desta pesquisa, optou-se por identificá-los por letras do alfabeto em ordem crescente, pela sequência de gravação das entrevistas.
} 
À luz das contribuições teóricas trazidas pelos autores de referência, deparamo-nos com um cenário que nos instiga a pensar. Atribuiremos aqui significado ao que denominamos Campo Capes, tendo como fio condutor Bourdieu, em ideias contidas em diferentes obras do autor referenciadas neste trabalho. Previamente, Valle (2017), na apresentação do livro Homo academicus, fundamenta-se em Bourdieu e explica a configuração do campo universitário, da qual destacamos:

Segundo uma concepção que pode parecer tipicamente "estruturalista", Pierre Bourdieu considera a sociedade como um conjunto de campos ou de "espaços de posições" e de disposições formalmente homólogos e imbricados hierarquicamente uns nos outros. Mas cada uma das partes desse conjunto obedece à mesma lógica de segmentação e de polarização. Ao olhar o campo universitário como campo social, como espaço dinâmico constituído por um conjunto de posições desigualmente desejáveis, ele evidência a oposição entre o que se poderia chamar de "polo mundano" e de "polo científico": o primeiro norteado pela competência cientifica, o segundo pela competência social. (Valle, 2017, p.18).

Ao tomar como objeto o assim chamado Campo Capes, passamos a pensá-lo como um espaço de posições e disposições que segue uma lógica científica. Pensar no assunto significa, para a pesquisa, encontrar uma forma de refletir sobre a influência que tem sobre o processo formativo na Pós-graduação stricto sensu, bem como seus efeitos sobre a performatividade discente. Afinal, quem é a Capes? O que os estudantes compreendem sobre ela? O que é possível fazer ou não em relação a esse sistema? E como são organizadas as nossas atribuições dentro dela?

Definimos Capes como um campo pela perspectiva de Bourdieu (2004, p. 22), para quem "[...] as pressões externas, sejam de que natureza forem, só se exercem por intermédio do campo, são midiatizadas pela lógica do campo". O Campo Capes, portanto, está atrelado ao campo científico (Bourdieu, 1983) e ao campo universitário (Valle, 2017). Para Bourdieu (1983) mostra que a troca de conhecimentos entre os cientistas se dá por meio de um modelo que está fundado na noção de capital, de forma a permitir a acumulação do chamado "crédito científico". É justamente a análise de acumulação desse "crédito científico" entre os pesquisadores que se define a classificação feita pela Capes. É um sistema que implica atuação, produção, performance. É formado por critérios avaliativos que compreendem todos os níveis dos sujeitos envolvidos, sejam docentes, discentes, coordenação ou até mesmo a 
instituição de Pós-graduação. Esse campo vem a ser um território formado a partir de disputas entre os agentes pesquisadores, já que ele oferece alguns subsídios como bolsas de apoio e financiamento para a Pós-graduação, sendo esse o "prêmio" desejado por todos no momento de ingresso nos cursos de mestrado ou doutorado.

Durante o desenvolvimento deste trabalho, foi possível observar, através dos dados levantados, que, entre as duas instituições pesquisadas (Unochapecó e UFFS), são poucos os estudantes cujos perfis enquadram-se no que a Capes espera. A maioria deles não dedicam tempo exclusivo à formação, o que fragiliza a produção e, consequentemente, a avaliação, tanto interna como externa. Há um desequilíbrio entre as dimensões "quantitativas" e "qualitativas" da avaliação, outro tópico abordado pela Fórum Nacional de Pró-reitores de Pesquisa e Pós-graduação das Instituições de Ensino Superior Brasileiras (Foprop), no qual destaca-se que:

Prevalece uma concepção quantitativa na avaliação e o peso numérico estimula os programas a buscar uma prática "produtivista" exagerada que, em muitos casos, resulta em produção de baixa qualidade e de baixo impacto. O "produtivismo", quando transformado em cultura acadêmica no interior dos programas, tende a negligenciar a fundamental importância da formação do pós-graduando. Nessa perspectiva, quantas dissertações e teses resistiriam a uma avaliação qualitativa? Uma avaliação que valorize mais os aspectos qualitativos dos programas exige revisão dos quesitos de avaliação. (Foprop, 2017, pp. 03-04)

A produtividade em alta escala, a esquizofrenia acadêmica em busca de produções e publicações pode ser considerada uma deformação acadêmica na medida em que a qualidade dos conteúdos vai se esvaindo junto ao tempo. Tem-se, por vezes, um campo superficial do conhecimento, passando-se por cima do tempo da aprendizagem e desenvolvimento de habilidades que permitem a compreensão das teorias que subsidiam o pesquisador durante 0 processo formativo. Um dos pontos evidenciados pelo Foprop é este: o fortalecimento da dimensão formativa da Pós-graduação, o foco na qualidade e os impactos do programa na sociedade, via egressos. Essa também é uma necessidade que os próprios mestrandos apontam como algo que deve ser repensado no âmbito da avaliação Capes. Todos esses elementos constituem o que denominamos como Campo Capes, formado por fortes tensões, mas que busca, através de diálogos e trocas entre pesquisadores docentes e discentes, um aprimoramento para alterações das regras já existentes. 


\subsection{Performance: equação de tempo e escrita}

Publicar ou morrer? Talvez esse questionamento nos faça compreender o que se passa dentro da Pós-graduação. Bianchetti e Machado (2009, p. 53) intitulam dessa forma um de seus trabalhos e acrescentam termos como "(...) produtividade, competição, burnout, doenças do trabalho, intensificação, angústia, mediocrização, rankeamento, punição, publicação, redução de tempo, etc." Essas são, segundo os autores, expressões utilizadas por estudantes trabalhadores que vivenciam em seu cotidiano a pressão advinda das Instituições de Ensino Superior (IES) ou até mesmo do sistema Capes.

Ao destacar esses elementos, suscitamos uma reflexão acerca do modo como os estudantes se encontram na Pós-graduação. Desafios levantados por Bianchetti e Machado (2009) são o tempo e a escrita. Ambos são eixos centrais, já que tudo passa por esses elementos. A escrita é um exercício que demanda conhecimento, leituras e muito tempo. Escrever é sempre um desafio, mesmo para aquelas pessoas que fazem dela sua profissão. A construção se dá, mas através da persistência, do esforço do pesquisador e de sua capacidade de concentração e abstração do conhecimento para composição da escrita.

É estranho começar uma escrita. Quando podemos escrever? Quando organizamos um pensamento ou um sentimento? Nem todos os dias nos sentimos bem para isso; o que acaba dificultando o processo de composição do arsenal teórico exigido para organização do pensamento. Como nos coloca Marques (2001), são muitas as questões envolvidas, mas uma coisa é certa: só se escreve escrevendo! Como diz a expressão popular, para escrever e coçar é só começar!

Marques (2001) ajuda-nos a pensar um pouco sobre esse processo de composição da escrita de maneira didática e poética. Em uma de suas passagens, ele leva-nos a refletir sobre o tempo:

Há gente que não começa alegando precisar de tempo. Andam à procura não do tempo perdido, mas do tempo que não lhe dão. Falta tempo ou falta paixão? Qual o viciado que não encontra tempo e jeito para sua cachacinha no boteco? O tempo não é sólido que não se possa recortar em fatias para melhor distribuí-lo, nem é líquido sem consistência e densidade/duração apropriada. O tempo é pastoso, algo que se espicha ou comprime como se quer, que se amolda a nossos amores. Havendo paixão, não é preciso a cada momento ser alertado para o antigo preceito: nulla die sine linea. A cada dia se encontra como escrever alguma linha que seja, desde que o escrever seja cachaça, não obrigação insípida. (Marques, 2001, p. 17) 
O tempo do pesquisador é assim (ou ao menos deveria ser) pastoso, dilatando-se e comprimindo-se diante das variadas situações pelas quais passamos no decorrer de nossa formação. Porém, observamos, diante das leituras desenvolvidas, que a densidade desse tempo vem tornando-se cada vez menor, apesar de nossas paixões. Isso porque vivemos em um período em que somos avaliados pela quantidade de produções que desenvolvemos. Consequentemente, o nosso tempo acaba por ser reduzido, deixando poucas oportunidades para que possamos moldá-lo às nossas paixões. Vivemos uma verdadeira corrida de obstáculos!

Bianchetti e Valle (2009) enfatizam os efeitos dos processos de avaliação impostos pela Capes bem como a questão da produtividade, relatando o modo como os estudantes veem sua passagem de formação nesse cenário. Destacam resultados de entrevistas realizadas com acadêmicos, evidenciando a questão da qualidade do que é produzido com relação à pressão em publicar:

(...) tornamo-nos especialistas em amontoar fragmentos"; "requentamos diferentes versões do mesmo texto". Igualmente, (os estudantes) apontam a interferência destas exigências produtivas na sua qualidade de vida: assinalam que afeta seu lazer e seu descanso. Exemplar neste aspecto é a afirmação de uma das entrevistadas: "estamos vivendo um tempo em que o sábado ainda é sexta-feira e o domingo já é segunda-feira. (Bianchetti e Valle, 2009, pp. 06-07)

Em síntese, os pesquisadores acabam por dedicar-se aos produtos de suas pesquisas, a fim de produzir mais em menos tempo, elevando o número de publicações e ampliando a área de abrangência de seu produto. É nesse contexto que Bianchetti e Valle (2009) inserem a discussão sobre o capitalismo acadêmico, “(...) 'surto produtivista', complementado por um 'surto competitivo', ambos traduzidos pela forte amarração entre fomento e avaliação dos programas de Pós-graduação" (Bianchetti e Valle, 2009, p. 56).

O foco da pesquisa é redirecionado. A produção capitalista assume um novo perfil e a Pós-graduação muda sua meta: de formação de professores para o ensino superior passamos à formação de pesquisadores. Tal mudança ocorreu em meados da década de 1990. A partir desse período, o encurtamento dos prazos acabou por atingir a comunidade científica, de forma mais direta os pesquisadores, no que se refere aos prazos para entrega de suas teses e dissertações. 
Os pesquisadores sofrem efeitos dessas mudanças, pois passam a ser condicionados e vigiados pela Capes conforme suas produções. Não há fronteiras entre este modelo e a autonomia acadêmica. Ou produz, ou produz. O tempo não é levado em consideração. O que se deseja é um pesquisador ideal, que adapte suas condições para atender a demanda produtivista, visando ao rankeamento e à promoção de um nome ou de uma instituição.

Voltamos à lógica da esquizofrenia acadêmica e da corrida de obstáculos, em que os pesquisadores enfrentam uns aos outros a fim de chegar à excelência em produção científica, movendo-se dentro de campo sem dependências, com intuito de garantir financiamentos, trabalhando com imediatismos. Na seção que segue, apresentamos o percurso metodológico do estudo que visou analisar a questão da performatividade acadêmica, na voz dos pósgraduandos.

\section{Metodologia}

\subsection{Enfoque}

A pesquisa desenvolvida, de cunho qualitativo quanto à abordagem do problema e exploratória quanto ao escopo, buscou produzir compreensões sobre a cultura da performatividade discente no contexto da Pós-graduação em Educação. A abordagem qualitativa foi considerada adequada aos objetivos deste estudo, tendo em vista que: permitiu compreender e caracterizar os critérios utilizados pela Capes para avaliação do desempenho discente, possibilitando refletir sobre o processo avaliativo e aspectos ligados à produção do conhecimento; e contribuiu para a investigação de implicações causais dos efeitos da performance discente sobre os programas de Pós-graduação em Educação.

\subsection{Unidades de Análise}

O campo de pesquisa foi delimitado no intuito de dialogar com mestrandos dos programas de Pós-graduação em Educação ${ }^{6}$ da Universidade Federal Fronteira Sul (UFFS), e da Universidade Comunitária da Região de Chapecó (Unochapecó), ambas localizadas no oeste de Santa Catarina. A análise se concentrou no percurso discente e nas tensões inerentes ao processo de formação na Pós-graduação stricto sensu. Para tanto, foram selecionadas duas turmas ingressantes em 2016/2 e que, portanto, encontravam-se em fase

\footnotetext{
${ }^{6}$ A pesquisa delimitou como campo a região oeste de Santa Catarina, portanto, contempla somente as duas universidades citadas.
} 
de qualificação e defesa de suas dissertações. Com esse recorte, chegou-se ao universo de 37 estudantes. Após mapeamento, foi estabelecido contato com todos os matriculados nessas turmas. Na UFFS, de vinte estudantes, obtivemos retorno de apenas quatro. Na Unochapecó, utilizando os mesmos procedimentos, de um total de dezessete estudantes, apenas oito concordaram em participar deste estudo. Imersos em suas pesquisas, muitos estudantes de ambas as instituições, justificaram a não disponibilidade de tempo para colaborarem. O perfil profissional dos estudantes que procuram essas instituições, como pode ser visto pela amostra desta pesquisa, também precisa ser considerado. A maioria deles (8 de 12) possuírem vínculo empregatício, demandando a atuação profissional, ao mesmo tempo em que se dedicam aos estudos da pós-graduação. Então, de um universo de 37 mestrando/as, realizamos 12 entrevistas.

\subsection{Técnicas de Coleta de Dados}

A coleta de dados se deu através de entrevistas com os estudantes. O convite foi feito via e-mail. Os estudantes que participaram demonstraram estar entusiasmados e curiosos com o resultado final do estudo. Realizamos 11 entrevistas pessoalmente e uma-via Skype, uma experiência positiva para a pesquisa, pois permitiu explorar uma tecnologia e obter bons resultados.

As entrevistas foram realizadas em data, local e horário combinado com os participantes, respeitando os princípios éticos estabelecidos. Foi seguido um roteiro e utilizado gravador de voz para registrar os dados, sendo as entrevistas transcritas para análise e compreensão. Ainda, as bases de dados do Currículo Lattes/CNPq e a Capes, especificamente documentos normativos, forneceram elementos para compreender os processos de avaliação do desempenho discente.

A pesquisa seguiu as indicações e exigências estabelecidas pelo Comitê de Ética em Pesquisa. O projeto foi aprovado em 30 de agosto de 2017, sob o protocolo 085698/2017, permitindo a coleta das materialidades empíricas. Também, de modo a assegurar os procedimentos éticos na coleta de dados, todos os entrevistados assinaram o Termo de Consentimento Livre e Esclarecido (TCLE).

\subsection{Procedimento de Análise}

Realizar uma análise sob as ideias de múltiplos agentes que compõem determinado espaço dentro de um campo científico não é tarefa fácil, para tanto, elegemos como método a 
Análise Textual Discursiva, ancorada em três elementos: “(...) desconstrução dos textos do corpus, a unitarização; estabelecimento de relações entre os elementos unitários, a categorização; captação do novo emergente" (Moraes, 2003 p.192).

Esses elementos são chave de leitura do corpus obtido através das entrevistas realizadas com os estudantes dos PPGs. Como nos coloca Moraes (2003), o corpus representa as informações da pesquisa, ou seja, a materialidade empírica do pesquisador. $\mathrm{Na}$ etapa de desconstrução dos textos do corpus, ocorreu a separação e fragmentação a partir da leitura e compreensão de cada resposta dada, sendo organizada a identificação para cada colaborador. O processo de categorização exigiu a construção de relações entre as unidades anteriormente fragmentadas e suas classificações para formação de conjuntos característicos mais complexos, ou seja, a formação de categorias. Ocorreram os processos de comparação entre uma unidade e outra, a fim de significar os elementos, agrupá-los ou separá-los. Definimos as unidades de significado-e, já com domínio do conteúdo, iniciamos a organização dos dados.

Cada fala já codificada foi recortada para agrupá-las por proximidade em unidades de significado, das quais emergiram três categorias: (i) Expectativas: muros ou pontes? (ii) Movimentos construtivos e processo formativo e (iii) Mecanismos de regulação e performatividade.

\section{Os resultados: as categorias emergentes}

\subsection{Expectativas: muros ou pontes?}

Parece que tá todo mundo certo e eu na contramão do mestrado... Me sinto deslocada, sabe? $(J 05,2018)$

Do mundo para o mestrado em Educação!

Pluralismo de ideias, formações distintas, pensamentos díspares.

Qual a primeira sensação? De ser e continuar sendo diferente dos demais!

Mal sabem os estudantes que a sensação é semelhante para todos, que passam pela mesma angústia, pelo mesmo medo e sensação de incertezas. E o que é pior? Não existem trocas internas sobre isso, algo que, a nosso ver, merece atenção.

Algumas falas dos estudantes indicam que toda essa sensação é resultado do contexto vivido, dos processos formativos, do diálogo e das leituras que são feitas, ou seja, são resultados do capital científico agregado ao longo da vida acadêmica. Não há como negar que 
o processo de construção é sempre mais rico quando se convive com pessoas que possuem um capital científico maior que o seu, pois a tendência é de somar conhecimentos, motivando a ampliação da experiência teórica e metodológica para poder dialogar de modo igual com o próximo e estabelecer relações análogas dentro de determinado campo. Porém, todo esse processo de construção não se dá de maneira tranquila. O campo da Pós-graduação é formado por tensões, por vigilância e pressão contínua durante o percurso formativo, tornandose ainda maior na reta final da escrita e análise dos dados.

Tomamos como eixo inicial as expectativas. As entrevistas mostram que os estudantes possuem muitas expectativas ao ingressar no mestrado. Cada uma varia de acordo com a área de formação dos mesmos, porém todas estão voltadas para o processo formativo. Em relação ao mestrado, alguns colaboradores nos colocam:

Eu esperava assim, que fosse mudar minha vida, e realmente mudou de muitas formas diferentes, mas não da maneira conforme aconteceu sabe, porque, você tem um pouco de noção, mas não tem a real noção do que é o mestrado antes de você entrar, sabe? Eu lembro que no primeiro semestre eu chorei muito, porque eu pensei, meu Deus, o que eu estou fazendo aqui?!!, Porque era aquilo que eu queria, eu tinha certeza que era aquilo, só que a gente acaba se deparando com uma realidade que não imaginava que era daquele jeito. (D02).

Ingressar em um mestrado é um prestígio/privilégio que muitos estudantes almejam e a expectativa é de que, de alguma forma, isso mude suas vidas. Porém, atender às demandas dos docentes e do próprio programa não é tarefa fácil.

Devido à pluralidade existente no interior do curso, muitas vezes os estudantes sentemse perdidos, sem saber que rumo tomar. As expectativas são grandiosas em relação ao conhecimento, aos professores e à própria instituição. Porém, as frustrações alcançam um nível bem significativo, como mostram os depoimentos apresentados. Falar de expectativa fez brilhar os olhos de alguns estudantes, como revela D02:

Sabe que eu acho uma coisa muito engraçada, porque quando eu olhava as pessoas que estavam no mestrado eu pensava "Nossaaaa, aquela pessoa está no mestrado, ela é top", entendeu, "ela é referência, ela passou no mestrado". O engraçado é que quando a gente entra no mestrado a gente se depara com aquele negócio e diz "meu Deus, é isso aqui que é o mestrado?" Sabe, e as pessoas que estão de fora te olham, “nossa, ela tá no mestrado!!!", como se fosse aquele negócio longe, quase impossível. 
E quando a gente entra, é só o mestrado, mas aí fica com aquela perspectiva do doutorado: "Nossaa, aquela pessoa tá no doutorado", a perspectiva é grande. (D02).

As surpresas e expectativas tomam conta dos mestrandos. Como relata a estudante, a titulação que está sendo planejada durante o percurso possui um peso muito grande, pois representa uma conquista social e intelectual. A visão que os mestrandos têm é de que se exige deles uma postura completamente diferente daquela cobrada dos sujeitos "comuns". A partir do momento em que se entra em um novo campo, como mestrando, esperam-se efeitos a curto prazo dessa caminhada. Socialmente, espera-se que o mestrado resolva os diferentes problemas existentes no meio educacional, "Ela é referência, ela passou no mestrado (...)" (D02). Porém, esse campo (mestrado) não é formado por caminhos pré-definidos ou acabados. Ele é constituído de reflexões, exigindo do estudante a capacidade de tencionar e de se fortalecer nesse espaço, através do habitus.

Os estudantes destacam que, ao mesmo tempo em que ocorre um amadurecimento intelectual, surgem também as angústias, pois é nesse processo de amadurecimento que se compreende o que é o mestrado. O estudante D05 destaca sua preocupação quando cita: “(...) preciso entrar e me adequar ao sistema, ao modelo que se espera". Estar dentro dos parâmetros é corresponder à performance que o curso espera". Ball (2004) destaca que a performance no campo da Pós-graduação se dá por via da produção. A performance do pesquisador é o elemento que garante o seu movimento nesse universo.

Em contraponto aos estudantes que se adéquam às normas dos programas e atendem às exigências da Capes, há aqueles que sofrem com a performance exigida nessa cultura acadêmica.

Não, não, me sinto até um fracasso!! Me sinto assim, meu Deus, parece que sou uma farsa, que eu não mereço estar aqui, entende? Que outra pessoa se tivesse no meu lugar estaria fazendo coisas melhores do que eu. Às vezes eu sinto que minha pesquisa não é importante, outras vezes eu sinto que eu não consigo entender alguns livros e isso me deixa abalada. Eu me sinto burra, eu sou muito burra! (J05).

Compreendemos que esse processo é resultado das condições dos mestrandos. Do tempo que possuem para se dedicar às leituras e ao processo formativo como um todo, das bolsas de estudo e dos financiamentos. Há uma assimetria entre as condições que eles têm e as exigências do curso que muitas vezes vai além do que imaginavam. 
À medida que os estudantes se adaptam aos programas e avançam na caminhada acadêmica, os horizontes começam a se expandir. Porém, esse progresso é lento. As coisas só passam a fazer sentido a partir do momento em que os mestrandos se apropriam de seus objetos de pesquisa e se colocam como pesquisadores, assumindo esse papel de maneira ativa. É nesse momento, a partir das trocas, "(...) na afinidade do habitus, vivida como simpatia ou antipatia" (Bourdieu, 2017, p. 23), que se fortalece a trajetória acadêmica e social do estudante, mesmo que ele não perceba ou não tenha consciência de sua existência.

Porém, mesmo nesse cenário de buscas e trocas, as relações são conflituosas, pois na medida em que se busca construir conhecimentos, os movimentos no campo científico começam a surgir. A pesquisa é uma ferramenta que possibilita esses movimentos, pois gera conhecimento, um produto final que precisa ser destinado para algum lugar. Esse lugar é denominado como veículo de publicação, ou seja, eventos, revistas, livros, periódicos, que permitem a divulgação dos resultados que vão sendo constituídos conforme a performance de cada estudante nesse espaço/campo. A pesquisa apresenta-se como um caminho viável para qualificar o capital científico: "Tenho tantos artigos em meu Lattes", "Participei de tais e tais projetos de pesquisa" "Sou mestre!". Tal discurso está presente no meio acadêmico.

Quando falávamos em pesquisa, em indagação, alguns estudantes apontaram-na como veículo de aprofundamento teórico. O sistema induz os estudantes ao alcance de um prestígio e Ball (2005) ressalta sua preocupação em relação a esses fatores de solidariedade e tempo/qualidade. Vivemos em uma era de formação rasa e rápida, seguindo o fluxo de uma linha de produção: de acordo com Ball (2005, p. 554), "cada vez mais, escolhemos e julgamos nossas ações, e elas são julgadas por outros, com base na contribuição que fazem para 0 desempenho organizacional, apresentado em termos de resultados mensuráveis. As crenças não importam mais - é a produção que conta".

E chega um momento do percurso formativo em que todos passam por isso. Os estudantes das duas IES aqui analisadas precisam cumprir critérios de desempenho, Atividades Curriculares Complemantares (ACCs), bem como corresponder aos critérios exigidos pelas políticas de financiamento. Logo, focam em seus objetos, em suas produções, buscando produzir seus produtos que precisam ser encaminhados para o destino final. Cumprir as ACCs ou morrer? Preencher o Lattes ou morrer? As obrigações são muitas. 0 tempo é curto. Por esse motivo começa-se, como nos aponta D06 a "(...) dar tiro pra tudo que é lado"; "(...) queira ou não é uma linha de produção, um chão de fábrica por assim dizer" (F06), no qual quem produz mais acaba ganhando mais prestígio acadêmico e social. 


\subsection{Movimentos construtivos e processo formativo}

Cada pessoa é única e possui um estilo de trabalho. O sucesso de uma parceria vai depender do modo como os atores - orientador/orientando - conduzem o processo e respeitam as diferenças existentes entre um e outro, bem como os horizontes que cada um pretende alcançar.

Nesse sentido, o orientador aparece como elemento importante na fala dos entrevistados. Os caminhos da pesquisa são sempre guiados pelo orientador, e este se torna referência para o estudante onde quer que esteja. Porém, nem sempre as relações acontecem do modo como cada um esperava. Há quem se sinta perdido com as orientações e também quem veja em seu orientador uma luz no fim do túnel:

Vejo que peca um pouco na questão do tempo da orientadora, até porque eles acham que a gente, ingressando no mestrado, a gente já tem autonomia de escrita sozinha, de organização, mas a gente entra um pouco perdido. Isso eu senti assim quando eu entrei em relação à orientação: ela tá mais distante, de eu ter dúvida e não ter assim muito pra quem recorrer, aquela ansiedade, que acredito que seja normal. (A03).

Ela tem a medida certa sabe? Da cobrança, do estímulo, quando ela precisa me chamar a atenção em algum aspecto que não tá indo bem ela primeiro potencializa. Então pra mim ela é uma pessoa adequada ao programa, sabe? Ela é diferenciada eu diria. (H03).

A relação que se constrói entre orientador e orientando se dá via monitoramento da produção intelectual, já que o docente também está sendo vigiado por um sistema e precisa apresentar resultados, atendendo às exigências temporais impostas pela IES e pela própria Capes. Sendo assim, os orientadores esperam autonomia dos estudantes. A mestranda A03 destaca sua preocupação com esse despreparo acadêmico, o que provoca insegurança nas tomadas de decisão referentes aos caminhos a serem seguidos. Viana e Maria (2008) nos fazem refletir sobre essas relações:

Orientador e orientando são pessoas que se encontram para compartilhar uma caminhada, por opção ou por imposição, dependendo do programa. Entretanto, é bom lembrar que ambos são seres humanos, dotados de sentimentos ambíguos que podem fazer a relação oscilar do amor ao ódio, da aceitação à rejeição, como todas as relações que fazem parte da convivência humana. (Viana, 2008, p. 96) 
Apesar das diferenças, precisa-se de bom senso para que as relações se solidifiquem e entrem em equilíbrio. O orientador sofre tanta pressão quanto o orientando, pois, a Capes institui metas em todos os níveis, levando também o docente a ser produtivo e competir com seus colegas. Mas ao mesmo tempo, ao longo da trajetória de formação surge uma grande amizade entre meio à aprendizagem, algo que não pode ser esquecido, pois enriquece e solidifica a formação como um todo.

De acordo com Bourdieu (2017, p.128), "o sucesso de uma carreira universitária passa pela 'escolha' de um orientador poderoso, que não é necessariamente o mais famoso nem mesmo o mais competente tecnicamente". Basta que tenha a medida certa e que para seus orientandos seja, o cara.

Frio na barriga, mãos suadas, nervosismo. Significado? Primeiro encontro com o orientador. Seres humanos possuem sentimentos que perante algumas situações não podem ser ocultados. No primeiro ou nos primeiros encontros com os orientadores, ter essas sensações é inevitável justamente pelo fato de, como nos coloca Bourdieu (2017), existir uma relação de poder. Nos primeiros encontros é que se constroem os laços afetivos entre orientador e orientando, ou o inverso disso. Eles ainda vão denominar se a relação entre ambos será um vínculo de dependência ou de libertação, inspiração ou barreira, evolução ou crise, crescimento ou deterioração, afeto ou indiferença, um "bom, ou mau gosto" etc.

Os efeitos das escolhas serão visíveis durante todo o percurso formativo, seja em relação à instituição, curso, linha de pesquisa, orientador ou objeto de investigação. Todos esses elementos constituem o campo macro da Pós-graduação e a performance discente está atrelada ao modo como o mestrando se movimenta em cada espaço, driblando ou não ou mecanismos de regulação existentes.

\subsection{Mecanismos de Regulação e Performatividade}

Cerca de $90 \%$ dos estudantes preocupam-se com o tempo. Seja por conta de prazos nas disciplinas, leituras, produções e participações em eventos, e principalmente com o tempo da dissertação:

As angústias maiores, acho que são com o tempo, né. A gente tem um tempo estimado pra terminar a dissertação e, assim, tem uma certa pressão pra que não tenha prorrogação de prazos né. Então a gente fica nessa angústia do tempo mesmo. (E03). 
Outra coisa que eu acho importante, que o tempo fosse maior, porque eu vejo que as disciplinas são muito importantes, mas o nosso amadurecimento acontece depois que elas acabaram. O tempo pra mim foi um problema (...) o tempo é uma coisa que nos aprisiona e nos impõe certas dificuldades. (H03).

O tempo para o pesquisador é angustiante. Marques (2001) leva-nos a pensar, apontando para os moldes que ele pode introduzir aos pesquisadores:

O tempo não é sólido que não se possa recortar em fatias para melhor distribuí-lo, nem é líquido sem consistência e densidade/duração apropriada. O tempo é pastoso, algo que se espicha ou comprime como se quer, que se amolda a nossos amores. (Marques, 2001, p. 17)

O tempo comprime-se diante das variadas situações existentes no decorrer da formação. Os mestrandos vivem uma corrida de obstáculos, na qual os ponteiros do relógio representam a Capes e as atribuições que devem ser cumpridas. Os mestrandos precisam ultrapassar esses ponteiros. Porém as engrenagens que sustentam e movimentam o sistema parecem ter uma energia inesgotável. Aos estudantes cabe alimentar-se das teorias que lhes convém, ampliando seus conhecimentos para assim apropriar-se de seu espaço de movimento em meio às engrenagens da Capes.

Há de se considerar, como nos colocam os estudantes, que o amadurecimento teórico é fundamental nos processos de aprendizagem. Entretanto, isso nem sempre ocorre no âmbito da pós-graduação, pois vivemos hoje um aceleramento formativo. Bianchetti e Valle (2014) contribuem:

Uma das questões que tem sido objeto de críticas e de importantes reações diz respeito à categoria 'tempo' e ao seu redimensionamento no trabalho acadêmico. As mudanças concernentes a essa categoria afetam os pesquisadores de diferentes formas: tanto no aspecto institucional dos programas - trabalho de orientação com a redução do tempo dos mestrados e doutorados - quanto na produção do conhecimento. (p. 98)

O tempo não está sozinho nessa luta pela produção do conhecimento. Junto dele outros elementos exercem forte influência sobre a performance dos estudantes. Frustrados e perdidos! Sentimento que prevaleceu à medida que eram realizadas as entrevistas. Destaca- 
se a pressão como unidade de significado. O desconhecido, a estranheza, as angústias, etc. criaram um sentimento de incerteza que os levou a viver sob pressão:

Eu pensei, ah, é um mestrado em educação, mas ele vai me trazer bastante pro (sic) meu campo de atuação e na verdade não é isso né, é você ir muito às origens, à epistemologia da educação, você conhecer as origens de onde surgiu a teoria que você atua na prática, então isso me assustou um pouco no começo. (B02).

No primeiro semestre eu parei e me perguntei: O que eu estou fazendo aqui dentro? Eu me sentia burra perto dos colegas, eu me sentia ignorante, meu conhecimento em filosofia não é nada, em história é mínimo, e eu percebi que tudo isso me faltou. Aí vinha leitura daqui leitura de lá, e eu não li tudo. Eu não imaginei que seria tão massacrante, bem, sinceramente. Não imaginei mesmo que eu me sentiria tão inútil no percurso das aulas. É frustrante demais você ter um monte de leitura e não dar conta de ler tudo. Eu nunca consegui ler tudo. (G02).

A pressão de não conhecer o terreno em que se estava pisando (no caso das teorias), acaba gerando uma preocupação e desconforto muito grande. Os estudantes são selecionados, entram no campo, e agora? $O$ que devem fazer? Arcar com as responsabilidades? Não aguentar a pressão e sair do jogo?

A noção que se tem ao verificar as falas é de que há sofrimento ao se fazer mestrado. É uma dor diferente. Dói não saber a quem recorrer, dói saber que os prazos estão chegando e os estudantes ainda têm muito por fazer. Dói saber que os critérios avaliativos são iguais para todos, independentemente da região, da instituição ou das condições culturais de cada mestrando.

"Meu Deus, minha cabeça não está mais funcionando" (K02). Esse enunciado está presente de diferentes formas na fala de muitos estudantes/trabalhadores, ao adentrar no campo e iniciar as leituras e discussões. Mesmo não dando conta, extrapolam-se os limites físicos e emocionais dos pesquisadores, sendo que, se desejarem permanecer, precisam aderir às normas e se moldar ao que é proposto, como dizem Bianchetti e Machado (2009, p. 54) "cabendo aos pesquisadores aderir... ou aderir!".

Associado à pressão, temos o processo de escrita. Ao dialogar com os estudantes, muito se fala do "como vou pôr isso no papel?". Falar sobre a pesquisa, sobre o objeto a ser estudado, sobre metodologia e todo esse caminho de formação é bom, é tranquilo. Porém, 
codificar tudo o que é dito, de maneira escrita, acaba tornando-se um processo doloroso, ainda mais quando se vive a pressão descrita anteriormente.

Os estudantes sofrem com isso. Na prática, grosso modo, é tudo muito tranquilo. As vivências da pesquisa encantam e fazem com que se queira ir muito além. Porém, o registro acaba fazendo com que o estudante crie certa aversão pela pesquisa. Para tudo há regras, o que dificulta a estruturação do pensamento na hora de escrever. É necessário ter um texto bonito, com palavras deslumbrantes, mas qual o sentido se ele perder a identidade? A mestranda K03 expõe suas angústias:

Cara, você tem que ter uma super justificativa, mas na prática ela é cobrada de forma bem instrumental. Eu diria que é publicação e só é válida se for em um veículo reconhecido. (K03).

A preocupação com os resultados da produção na avaliação dos programas (artigos e periódicos) é cada vez maior. Publicações em veículos qualificados é parâmetro fundamental para se atingirem as melhores notas no sistema e, assim, ter acesso a mais recursos e reconhecimento. A escrita, nesse caso, é fundamental, pois garantirá as publicações e o prestígio acadêmico e institucional.

Publicar? Alguns estudantes relataram que nunca haviam publicado na vida, então além de toda a adaptação em um novo processo formativo, local que de acordo com relatos "Eles pensam que a gente já tem todo um conhecimento e autonomia suficiente", ainda se faz necessário aprender a escrever.

Os estudantes destacam suas angústias e dificuldades com o sistema Capes. Estes dados merecem um olhar atento:

Às vezes parece que tu nem publica algo com tanta qualidade, mas que precisa, no teu currículo tem que ter que você publicou algo, vejo que isso interfere enquanto estudante. Quando a gente inicia a primeira coisa é o currículo lattes, e já tem que colocar tuas publicações porque é uma exigência da Capes, tanto pra nós enquanto estudante quanto pra universidade enquanto programa. A Capes interfere acho que quase $80 \%$ dentro do programa. (A06).

O que mais os pós-graduandos ouvem são frases no imperativo: alimente o Lattes, cumpra os créditos de disciplinas, faça prova de proficiência, realize o estágio de docência, 
participe de eventos, publique, publique, publique, isso tudo além do trabalho, já que nem todos-têm acesso a bolsas de estudo e conseguem dedicar-se apenas ao mestrado.

Cabe destacar que essa é a realidade de duas IES do Oeste de Santa Catarina e os dados apontaram que não existem diferenças significativas entre um programa e outro no sentido da performatividade discente. Estudantes das duas universidades mantêm vínculo empregatício, sufocando-se com o tempo de estudos e produções científicas. Apenas quatro deles afirmaram não trabalhar, por serem bolsistas Capes, Taxa ou do Programa de Bolsas Universitárias de Santa Catarina (Uniedu), todos com 20 horas ou mais.

Todo esse processo formativo produz efeitos sobre os estudantes e docentes que estão ativos nesse sistema. Uma das maiores queixas é a regulação. Ela está presente em todo o processo formativo. O aluno sente-se regulado na escrita, nas leituras, com o tempo e todos os processos que permeiam a formação. Destacam que a primeira coisa exigida é o Lattes, pois ali se tem um controle via sistema de como está se dando a performance do estudante.

Aí a gente dá aquela desculpa: Ah, porque a Capes que dita às regras, porque a Capes não sei o que, porque a Capes disse que tem que fazer, mas a gente nem sabe direito o que tem que fazer, o que avalia, o que não avalia, o que dá ponto, o que não dá ponto, quem é a Capes? É um ser humano a Capes? Aí gente fala muito, e ainda fala brabo, "Ah, porque a Capes, diz pra fazer essas coisas, porque a Capes", né? e na verdade você me faz essa pergunta eu me sinto pequena porque eu nem sei tudo o que a Capes pode avaliar da gente, do programa, o que precisa. (D06).

Como exposto, o discurso dentro do mestrado é que o tempo está passando. Com ele muitas coisas aparecem, e a pressão torna-se cada vez maior. O campo, como se pode notar através dos fragmentos, é formado por tensões e sua estrutura define-se a partir das relações que são estabelecidas pelos agentes que dele fazem parte. A Capes, como órgão regulador, é considerada selo de qualidade que confere prestígio ao objeto de avaliação, neste caso, o curso de Mestrado.

O desenvolvimento da Pós-graduação no país é recente e os conhecimentos que se têm sobre suas políticas de avaliação são desconhecidos por muitos acadêmicos. Por isso o espanto: Quem é a Capes? Por trás da entidade, da sigla, quem é a Capes? É um ser humano? Quais os critérios de pontuação Capes?

A análise das entrevistas com os estudantes ouvidos por esta pesquisa mostra que este campo promove a preocupação com a performace quantitativa na produção acadêmica. 
Conforme colocado pela Foprop, já é cabível uma avaliação que valorize os aspectos qualitativos, caso contrário, a corrida atrás de publicações irá se acelerar mais intensamente, negligenciando os processos formativos e tornando os mestrandos cada vez menores no seu campo, pois o conhecimento científico irá se fragmentar a medida em que se institui uma formação enciclopédica.

A performance discente baseia-se também em indicadores temporais. A bolsa de estudos é um dos elementos que garante o mínimo de estabilidade para que consigam manterse de forma integral em um curso de Mestrado. De acordo com o levantamento de dados, os estudantes que possuem bolsa institucional 50 e 100\% continuam trabalhando, pois são isentos dessas porcentagens de mensalidades. Entretanto, há fatores externos/cotidianos que precisam ser atendidos, o que os leva a trabalharem em período integral, resultando na sobrecarga de atividades e fragmentação da formação. Além disso, o custeio para participação em eventos regionais, nacionais e internacionais exige investimentos, o que obriga o estudante a manter-se em dupla função.

O fato de cursar o mestrado em uma universidade pública não garante aos estudantes a condição de dedicar-se exclusivamente a ele, como evidenciado pelos participantes desta pesquisa. As demandas pessoais precisam ser atendidas, o que os leva a uma jornada intensa de trabalho, além do tempo necessário aos estudos e, assim, torna-se ainda mais difícil tender às enormes exigências do campo Capes.

\section{Conclusões}

Buscou-se, neste trabalho, investigar como se configura a cultura da performatividade (Ball, 2004; 2005; 2010) discente no âmbito da Pós-graduação stricto sensu brasileira, tendo como foco de análise os programas da área de Educação da região Oeste de Santa Catarina e como base os conceitos de campo e habitus de Pierre Bourdieu (1983; 2017). Esses sujeitosestudantes, ou agentes, como define Bourdieu, são submetidos a um sistema que exige produção em quantidade e qualidade em espaço temporal reduzido.

Tomando como base os 12 entrevistados desta pesquisa, analisamos como os pósgraduandos vivenciam a cultura da performatividade discente, medida pelo campo Capes, órgão regulador da pós-graduação no país, a partir de três categorias de análise.

Ao analisarmos a primeira categoria (Expectativas: muros ou pontes?), percebemos que, ao ingressarem no curso de mestrado, todos têm enormes expectativas em relação ao conhecimento, aos professores e à própria instituição da qual passam a fazer parte. Não 
demoram, porém, a se deparar com frustrações, como mostram os depoimentos apresentados, sobretudo pelas exigências de um sistema que não respeita as dificuldades individuais enfrentadas pelos alunos. Os estudantes da pós-graduação no Brasil, via de regra, precisam dar conta, ao mesmo tempo em que se dedicam aos estudos e à produção acadêmica, das demandas profissionais e de subsistência. Cria-se, nesse cenário, um sentimento de impotência, especialmente por sentirem-se à mercê do julgamento alheio, pela exposição via currículo e pela competitividade criada pelo Campo Capes. Como afirma Ball (2005), p. 554), "(...) as crenças não importam mais - é a produção que conta”.

A segunda categoria de análise (Movimentos construtivos e processo formativo) tomou como foco o principal produto dos cursos de mestrado, as dissertações, construídas no vínculo orientando-orientador. A relação expõe as dificuldades dos pós-graduandos e, também, dos professores-orientadores. Os entrevistados desta pesquisa levantaram pontos que são cruciais para as questões aqui em análise: se o campo Capes é exigente em relação à produção dos estudantes, também o é para o quadro docente desses programas, impondoIhes uma severa agenda de produção.

Por fim, a terceira categoria de análise (Mecanismos de regulação e performatividade) explicita o aceleramento do processo formativo na pós-graduação brasileira que se dá, muitas vezes, em detrimento dos processos de aprendizagem (Bianchetti e Valle, 2014).

Percebe-se que, se por um lado o campo Capes contribui para estabelecer importantes parâmetros para assegurar a qualidade dos programas de pós-graduação, por outro as políticas macroestruturais condicionam formas de atuar nesse espaço que não são pensadas de acordo com o contexto dos programas, atrelando os pesquisadores a formas rígidas de atuar nesse espaço.

É preciso considerar, entre os limites deste trabalho, o fato de os resultados da pesquisa aqui apresentada serem apenas um recorte da realidade vivenciada nos programas de pósgraduação brasileiros. Há uma série de questões, ainda, a serem analisadas neste campo. Entre elas, destacamos a importância de se avaliar os impactos das mudanças no processo avaliativo da CAPES, implementadas a partir do quadriênio que se inicia neste ano de 2021. A partir de agora, os programas passam por avaliações multidimensionais (Formação de pessoal, Pesquisa, inovação e transferência de conhecimento, Impacto na sociedade e Internacionalização). Resta saber o que essas novas demandas, entre outras tantas, trarão de novas exigências aos pós-graduandos, na luta por serem considerados sujeitos performativos. 


\section{Agradecimentos}

Agradecemos à Universidade Comunitária da Região de Chapecó (Unochapecó) pela bolsa institucional de 50\% e ao Programa de Bolsas Universitárias de Santa Catarina (Uniedu) pela bolsa de estudo concedida no segundo semestre, tornando possível a realização desta investigação.

\section{Referências}

Antonello, Ana Paula. (2018). A cultura da performatividade discente no contexto da pósgraduação em educação na região Oeste catarinense (Dissertacão de Mestrado). Universidade Comunitária da Região de Chapecó. Chapecó, SC, Brasil. Recuperado de

http://konrad.unochapeco.edu.br/pergamum/biblioteca/index.php?codAcervo=212731.

Ball, Stephen. (2004). Performatividade, privatização e o pós-Estado do Bem-Estar. Educação \& Sociedade, 25(89), 1105-1126. doi: https://doi.org/10.1590/S010173302004000400002

Ball, Stephen. (2005). Profissionalismo, gerencialismo e performatividade. Cadernos de Pesquisa, 35(126), 539-564. doi: https://doi.org/10.1590/S0100-15742005000300002

Ball, Stephen. (2010). Performatividades e fabricações na economia educacional: rumo a uma sociedade performativa. Educação e Realidade, 35(2), 37-55. Recuperado de https://seer.ufrgs.br/educacaoerealidade/article/view/15865

Bianchetti, Lucídio., e Machado, Ana Maria Netto. (2009). Publicar ou morrer!? Análise do impacto das políticas de pesquisa e pós-graduação na constituição do tempo de trabalho dos investigadores. Educação, Sociedade \& Culturas, (28), 53-69. Recuperado de https://www.fpce.up.pt/ciie/revistaesc/ESC28/28 lucidio.pdf

Bianchetti, Lucídio., e Valle, lone Ribeiro. (2014). Produtivismo acadêmico e decorrências às condições de vida/trabalho de pesquisadores brasileiros e europeus. Ensaio: Avaliação e Políticas Públicas em Educação, 22(82), 89-110. doi: https://doi.org/10.1590/S010440362014000100005

Bourdieu, Pierre. (1983). O campo científico. En R. Ortiz (Ed.), Pierre Bourdieu: sociologia (pp. 122-155). São Paulo, Brasil: Ática.

Bourdieu, Pierre. (2004). Os usos sociais da ciência: por uma sociologia clínica do campo científico. São Paulo, Brasil: Editora UNESP.

Bourdieu, Pierre. (2017). Homo academicus. Florianópolis, Brasil: Ed. da UFSC.

Dolz, Joaquim e Edmée, Ollagnier. (2004). O enigma da competência em educação. Porto Alegre, Brasil: Artmed. 
Fórum Nacional de Pró-reitores de Pesquisa e Pós-graduação das Instituições de Ensino Superior Brasileiras [Foprop]. (2017). Avaliação da avaliação da pós-graduação brasileira: contribuições do diretório nacional do fórum nacional de pró-reitores de pesquisa e pós-graduação. $\quad$ Recuperado de https://ppgedu.ufms.br/files/2017/06/AVALIACAO-DA-POS-GRADUACAOCONTRIBUICOES-DO-FOPROP.pdf

Marques, Mário Osório. (2001). Escrever é preciso: o princípio da pesquisa. ljuí, Brasil: Unijuí.

Moraes, Roque. (2003). Uma tempestade de luz: a compreensão possibilitada pela análise textual discursiva. Ciência \& Educação, 9(2), 191-211. doi: https://doi.org/10.1590/S1516-73132003000200004

Pereira, Marcelo de Andrade. (2013). Performance e Educação: (des) territorializações pedagógicas. Santa Maria, Brasil: Ufsm.

Santos, Lucíola Licinio. (2004). Formação de professores na cultura do desempenho. Educação \& Sociedade, 25(89), 1145-1157. doi: https://doi.org/10.1590/S010173302004000400004

Setton, Maria da Graça Jacintho. (2002). A teoria do habitus em Pierre Bourdieu: uma leitura contemporânea. Revista Brasileira de Educação, 8(20), 60-73. doi: https://doi.org/10.1590/S1413-24782002000200005

Trein, Eunice., e Rodrigues, José. (2011). O canto da sereia do produtivismo científico: O mal estar na academia e produtivismo científico, o fetichismo do conhecimento mercadoria. Revista Brasileira de Educação, 16(48), 769-819. Recuperado de http://www.scielo.br/pdf/rbedu/v16n48/v16n48a12.pdf

Valle, Ribeiro lone. (2017). Prefácio. En P. Bourdieu, Homo academicus(pp. 02-04). Florianópolis, Brasil: Ed. da UFSC.

Viana, Cleide Maria. (2008). A relação orientador-orientando na pós-graduação stricto sensu. Linhas Críticas, 14(26), 93-109. doi: https://doi.org/10.26512/lc.v14i26.3430 


\section{Revista indizada en}
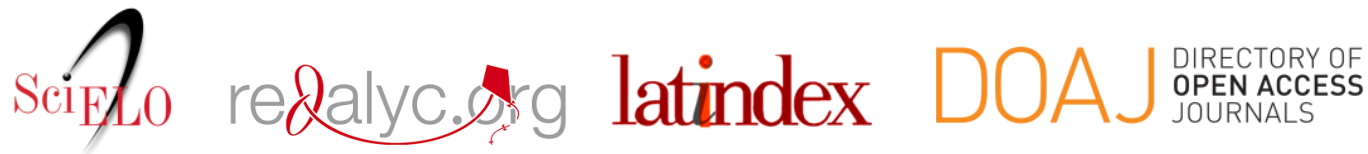

Distribuida en las bases de datos:

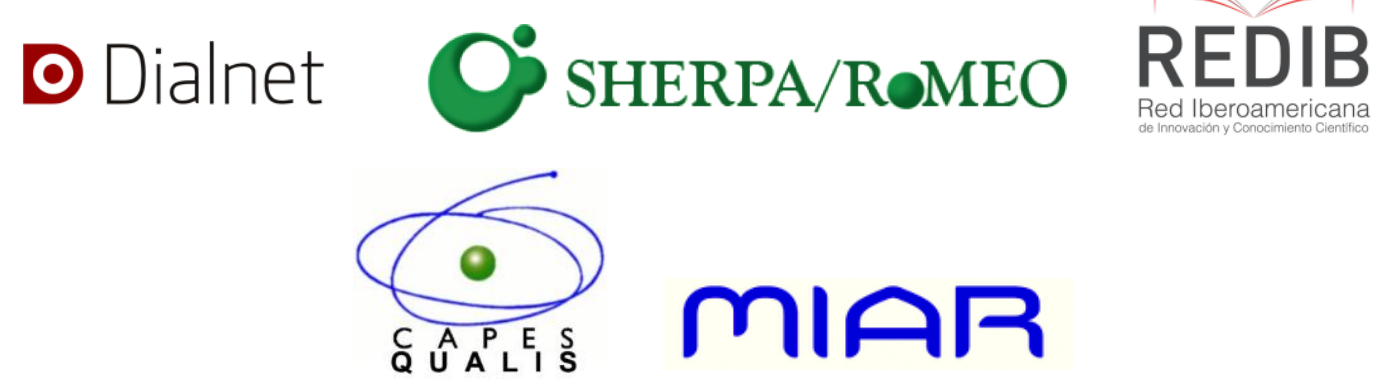

